\title{
Pervasion of what? Techno-human ecologies and their ubiquitous spirits
}

\author{
Mark Coeckelbergh
}

Received: 15 September 2011/ Accepted: 29 March 2012/Published online: 20 April 2012

(C) The Author(s) 2012. This article is published with open access at Springerlink.com

\begin{abstract}
Are the robots coming? Is the singularity near? Will we be dominated by technology? The usual response to ethical issues raised by pervasive and ubiquitous technologies assumes a philosophical anthropology centered on existential autonomy and agency, a dualistic ontology separating humans from technology and the natural from the artificial, and a post-monotheistic dualist and creational spirituality. This paper explores an alternative, less modern vision of the "technological" future based on different assumptions: a "deep relational" view of human being and self, an ecological view of human-technology relations, and "ubiquitous" spirituality. Moving beyond an ethics of fear and control, it is argued that technology is part of a lived and active whole that is at the same time human, technological, social, and spiritual. Influenced by ecological and Eastern thinking, it is concluded that an ethics of technology understood as a relational ethics of life asks us to adapt and grow within this multi-faced ecology, which is currently_but not necessarily—pervaded by hyper-individualist modernity and its ego-boosting technologies of the self. This growth is only possible by relating to, and learning from, other cultures and from their specific way of pervading and being pervaded.
\end{abstract}

Keywords Pervasive technology - Ubiquitous technology · Artificial intelligence $\cdot$ Ethics · Autonomy · Self · Ecology · Phenomenology $\cdot$ Spirituality $\cdot$ Buddhism $\cdot$ Taoism . Confucianism

M. Coeckelbergh ( $\square)$

Department of Philosophy, University of Twente, P.O. Box 217, 7500, AE, Enschede, The Netherlands e-mail: m.coeckelbergh@utwente.nl

\section{Introduction}

Contemporary information and communication technologies open up wonderful possibilities previous generations could hardly have imagined. In many domains of human activity, they give us new experiences and allow us to do new things. This seems true for so-called pervasive and ubiquitous technologies, which integrate networked electronic devices in everyday objects and everyday life. Artifacts such as mobile phones and GPS navigation devices pervade many of our activities. The internet itself is perhaps the greatest "pervader". And we tend to welcome them. We wish to be part of the networks. We yearn to connect and to remain connected. Who would want to return to the barren wastelands of permanent off-line existence? Who could reasonably want such a suicide?

However, when we reflect upon these changes and realize how "pervasive" these technologies are in a broader sense, indeed if we see how much they change the way we lead our lives, we may also become deeply concerned about the problems raised by these pervasive technologies and, more generally, we may worry about the darker sides of what is sometimes called the "information age". We may sense that perhaps we have lost something on the road to progress. Then initial enthusiasm might be replaced by fear: the fear that (artificially intelligent) technology "takes over", that it gets "out of control", that there is no room for the human in the machine, that the robots are coming and that the singularity is near, that we are crushed by a system that is blind to human ethical and existential concerns, that the machine will invade us and that we will become machines in a silicon world. After Copernicus, Darwin, Freud, and postmodernism, it seems that the human ego is now given a final and deathly blow by technology — at best a mercy killing that ends the 
torments of this most miserable of all creatures, at worst an event even the victim does not remotely care about. Then, we would have arrived at a point when, as Walter Benjamin wrote, mankind's "self-alienation has reached such a degree that it can experience its own destruction as an esthetic pleasure of the first order" (Benjamin 1936, p. 242). Can we avoid this techno-fascism, this summit of alienation and de-humanization?

Fear of technology and of losing control is not new; it is related to a well-known current in the Western culture, sometimes referred to as the "Frankenstein syndrome". Consider the ancient Greek myths of Prometheus, who stole fire from the gods and gave it to mortals, for which he was heavily punished by Zeus, or the story of Icarus, who made wings of wax but flew near to the sun, fell down, and died. In modern interpretations of these myths, technology is linked to the ancient Greek concept of hubris: we are arrogant if we think that we can control the world and control the technology; we cannot and we will pay for our arrogance. In modern times, we find the story of the sorcerer's apprentice (see e.g., Goethe's poem Der Zauberlehrling), who enchants a broom but then loses control. There is also the legend of Faust who, in his pursuit of pleasure and knowledge, sells his soul to the devil. He becomes eternally damned. ${ }^{1}$ And of course, there is the famous story of Frankenstein's monster. Marry Shelley's 19th century novel, which, significantly enough, is subtitled "The Modern Prometheus", tells the story of Victor Frankenstein who created an artificial man, but then the "monster" turns against him. The animation of death matter, the creation of artificial life and intelligence, is punished. ${ }^{2}$

Most philosophers of technology have also been pessimistic about technological progress and in particular about modern technology. After the scientific and technological optimism of early modernists like Bacon and Descartes and of many Enlightenment thinkers, philosophers such as Heidegger, Jonas, Ellul, and Marcuse focused on the dark side of technology and of technological society. In spite of the differences in approach between these thinkers, they shared the view that modern technology, which was supposed to improve our lives, turned out to be a threatening and alienating force. The "New Atlantis" (Bacon 1626) proved to be less hospitable than foreseen. Technology, which was conceived as something that could help humanity, came to be seen as a threat to humanity and to society. We became cogs in the machine and mindless consumers. Our autonomy was violated by technology.

\footnotetext{
1 See also Goethe's play, although here Faust seeks transcendent knowledge and in the end he goes to heaven.

2 Note that the monster mourns over the body of his creator. It seems that the only thing we can hope for is that the intelligent artificial beings we will create, will also mourn the death of humanity.
}

Moreover, technology was also seen as a threat to spirituality. Weber argued that rationalization has also disenchanted the world (Weber 1919). In a world ruled by science and technology, it seemed there is no longer room for religion or spirituality. In modernity, we became our own gods by means of technology, but then were overruled by our own inventions. The human quest for knowledge and power is being punished; the story of human hubris is now coming to an end.

Viewed in this light, contemporary information and communication technologies - and pervasive technologies in particular-seem to aggravate our sad predicament. We invented the World Wide Web to liberate and help us, but we get trapped in our own creation and become the victim of large corporate and governmental spiders, which squeeze information out of us in order to make profit or to gain more power. We created e-mail to communicate faster, but now we have to work faster and harder. We invented mobile phones to gain more freedom and autonomy, but now we are tracked and monitored; we are supposed to be available $24 \mathrm{~h}$. In late modernity, Big Brother did not leave the scene, but became ubiquitous. We might fear that soon the network will even colonize the things we never knew had anything to do with information technology. It seems that the Internet of things will be the final defeat of human autonomy. Information technology will surround us and pervade us. They will be very small. They will be intelligent. They will be in us. We will be the system. Singularity will be realized at last.

Of course, this picture of contemporary technology is far too one-sided; it can and must be challenged. Perhaps we can retain some control over these technologies; perhaps our capacity of agency is not entirely eroded; perhaps pervasion is not total. We might even use the very same technologies to empower us, to exercise more agency; this is already happening. This is the other, more positive side of the story of technological progress. However, this paper has a different purpose. Both sides share the assumption that human agency and autonomy are to be protected and to be promoted. This paper asks if, when in our response to problems with contemporary information technologies"pervasive" and others-we put so much emphasis on agency and autonomy, we are asking the right kind of questions. In particular, it examines the philosophicalanthropological, ontological, and spiritual assumptions (broadly construed) that underlie the discussion and explores a view based on different assumptions. Thus, this paper is concerned with a broader meaning of "pervasion" than the one implied in present-day "pervasive" technologies; with its discussion it aims to open up a different discursive space where different questions can be asked and different visions of the technological future can emerge. 


\section{The Frankensteinian problem and its assumptions}

The usual response to ethical issues raised by pervasive and ubiquitous technologies assumes a philosophical anthropology centered on autonomy and agency. Psychologically, what is at stake is the defense of the borders of the human against potential invasions by technology. The human is a castle that must be protected. We erect walls and dig ditches. The human is sharply divided from the non-human; technology is seen as non-human. It can be used, but it remains and has to remain something alien. It is an instrument to realize human purposes, but the means (technology) and the end (the human) should be carefully kept separate. In philosophical jargon, we have to make sure that the subject does not become an object. It is emphasized that we are not things. As Sartre wrote, we are subjects and not "a kind of moss, or a fungus or a cauliflower" (Sartre 1946). If he were alive today, he might write, "we are subjects and not a kind of mobile electronic device; we are not an iPad." According to the modern view, there is a separation between me (the subject) and the world (natural and artificial objects) and we have to maintain that separation. Alienation is conceptualized as the invasion of the subject by the object - the colonization of the lifeworld by the system (Habermas 1984-1987). ${ }^{3}$ Ubiquitous technology seems to imply a kind of objectification: technology no longer appears as tools we use or through which we express our freedom and potentiality as human beings who wish to be subjects (this is the positive meaning of objectification we can find in Marx, see e.g., his Comments on James Mill), but rather technology appears as something alien that makes $u s$ alien as well: it pervades us and threatens to turn us into objects, we are in danger of becoming "mere things". Then, technology implies the violation and death of subjectivity rather than its realization. Remaining human means protecting the purity of your subjectivity, which should remain unpenetrated by the anything or anyone. The protection of humanity is a matter of ontological hygiene and chastity (Lat. castus means "pure"). Autonomy means protecting your castle from invasion: invasion by other people, but also invasion by the material. Subject and object must remain separated. As Berlin put it in his famous article "Two Concepts of Liberty":

\footnotetext{
${ }^{3}$ Note that this positive meaning of alienation as objectification is different from Marx's notion of alienation, which is about the alienation of the worker from his product, his work, his essence, and from others under capitalist conditions (see the Economic and Philiosophic Manuscripts of 1844)—although it might be interesting to explore potential links between the two (alienation from your essence as a human being might be a good starting point). And of course, Habermas's work is influenced by Marx.
}

"I wish my life and decisions to depend on myself, not on external forces of whatever kind. (...) I wish to be a subject, not an object; (...) I wish to be somebody, not nobody; a doer-deciding, not being decided for, self-directed and not acted upon by external nature or by other men as if I were a thing, or an animal, or a slave incapable of playing a human role (...)" (Berlin 1958, p. 203).

This definition of autonomy reflects the assumption that to become human is to take distance from the natural and the material, to pull yourself out of the dust and dirt of the earth. Human dignity ${ }^{4}$ is achieved by cutting off your ties with the beasts and by elevating yourself above matter; violation of human integrity is interpreted as a beastly and monstrous act, a transgression of the ontological and moral boundaries. Nothing merely earthly and beastly should be made human, and nothing human should be made earthly and beastly. The moral imperative is to let nothing alien invade your humanity, that is, your subjectivity. If you use technology, make sure it remains a mere tool, a mere thing. Use it for your purposes, but do not let it become the purpose.

In the West, the spirituality that goes with this view is rooted in monotheist creational thinking, ${ }^{5}$ which sets up a sharp divide between (the one) God and His creation. In contrast to nature relations, the earth is seen as a nonspiritual place, a stage on which the creatures perform their lives, but to which their spirituality is not intrinsically related. Spirit belongs to the one God, and spirituality means to connect to God's spirit, to receive His grace. There is no spirit in the natural and the material world. Keeping your spiritual purity means to wash off the dirt of the earth. Long before Weber wrote about disenchantment, the world was already disenchanted by monotheism-or at least there was already the idea of a non-spiritual earthly world. ${ }^{6}$ Moreover, the creator is kept separate from the creatures. In modern "secular" culture, the assumption that there is a strict divide between the creator (spiritual) and the created (non-spiritual) is maintained, but then with humans in the position of the creator. We create artifacts, but maintain a strict distinction between human creator (human dignity, human subjectivity, human ends, etc.) and the created (mere things, instruments, means, etc.). If anyone or anything crosses this divide, we have a

\footnotetext{
${ }^{4}$ There are other, more relational views of human dignity, also in the West, but they seldom include our relation to technology or materiality. (see footnote 7).

5 Note, however, that some other forms of religion-ancient or modern-may also be in line with it, for example, if and to the extent that they hold that only humans and gods are spiritual beings.

${ }^{6}$ The disenchantment thesis has been (rightly) criticized by several authors; I will challenge this thesis in the next section.
} 
"monster." Things-natural and artificial-are not supposed to touch the human center of value, meaning, and creational (quasi-) spirituality. Natural and artificial entities belong to the domain of facts, but this world has to be kept separated from the realm of values. The imperative for things is: Thou shalt not invade the castle of value, the realm of normativity, the domain of human value, the kingdom of ends. If there is spirit at all, it belongs to the human, and things have value only insofar as they are related to the original source. When craftsmanship is concerned, things may still have an "aura" derived from the craftsman's spirit, but, as Benjamin lamented, in the age of mechanical reproduction this aura is lost (Benjamin 1936). Just as modern "mass men" have been alienated from their divine creator, modern "mass products" have been orphaned from their human creator.

In the age of information technology, this alienation seems to only increase, since there is no longer an artifact. And who is the maker? There are only bits of "information", and their source is unclear. There are nodes in the network, but they are created by no one and by everyone. No spirituality, not even a spiritual aura, can be attached to these fluid elements, the metaphysical status of which is entirely unclear. It therefore seems best that we humans use it for our purposes, but maintain our ontological purity as subjects. Whatever information is, it is not human. Make sure that you guard your castle: they are everywhere. Ubiquitous technology is already knocking on the gates. Defend yourself and your dignity against others and against the objects that try to invade your space. Strengthen your philosophical firewalls against the monsters that try to cross the distinctions. Perhaps it is already too late.

Thus, setting up what we may call the Faustian problemgaining and maintaining human agency and autonomy in a technological world that threatens to alienate us-depends on what we may call these modern "works of purification" (Latour 1993). Only if we assume a dualist anthropology, ontology, and spirituality, can we define the problem in this way. This becomes clearer if we explore an alternative view of the relation between humans and technology.

\section{An alternative view: techno-human ecologies and their spirits}

The usual view of alienation and pervasion assumes that human beings interact with their environment, but are basically separated from it. There is a "relation" between human and environment, between subject and object, but this is a "weak" kind of relationality, since there remains a (normatively significant) gap between the two. If we assume a "strong" relational or "deep" relational view of the human, however, we get a very different problem formulation. Let us start from humans who are already connected to, and engaged in, their environment. In Western philosophy, such a view is suggested by phenomenological and ecological approaches. ${ }^{7}$ Heidegger used the term "being-in-the-world" for this existential relationality (Heidegger 1927) to criticize the subject/object split in the Western tradition. We are involved beings-there is no Cartesian split between consciousness and world, between mind and matter. Subject and object are strongly related. Similarly, ecology suggests that what we are dependent on our relations to the environment (see e.g., Callicott 1986).

In Buddhism, Taoism, and (to some extent) Confucianism, we also find a "deep relational" view of human being, a view which has fruitfully influenced Western thinkers. For example, the "embodied cognition" approach is inspired not only by the Western phenomenological tradition (e.g., MerleauPonty), but also by Confucianist, Taoist, and Buddhist thought (Varela et al. 1991, 1999). For Buddhists, the duality self/ world or subject/object is an illusion. Moreover, they reject the Hinduism notion of the true self. We do not 'have' a self. In this sense, the self is "empty" or non-existent (doctrine of "no-self"). We are not, we become, humans and everything else 'are' becoming. And although Taoism does not deny the ontological reality of the self, it recommends selflessness in the sense of leading a life in harmony with nature and society (Ho 1995). Confucianism also emphasizes relationships with (human) others and with the collective.

With regard to the relation between humans and technology, this "deep relational" approach to human being implies recognizing that we are always already related to technology as we act with things and live with things. Technology is not an external instrument, but is part of what we are and what we do. There is mutual pervasion, change, adaptation, and life. Without pervasion, without relationality, there is not real change; there is only death. If the self is relational, then there is no subject separate from the object. Human being implies subjects being already pervaded (and constituted) by "objects" —in a much stronger or deeper sense than in Marx. There is no longer

\footnotetext{
7 Note that there are other approaches within Western philosophy that may also inspire more relational and non-Cartesian thinking. For example, philosophers from the neo-Aristotelian tradition have emphasized the social and vulnerable nature of human being. For example, Nussbaum's version of the Capability Approach is partly based on the recognition that human dignity is grounded into our vulnerability, that human good crucially depends on others and that animals also have dignity (e.g., Nussbaum 2006, 2011). And MacIntyre has argued that vulnerability and dependency are central to human life and virtue, and that as embodied beings, we have much in common with animals (MacIntyre 1999). However, these views do not radically question dualist views of self and human being and remain non-relational when it comes to their assumptions about the relations between humans and technology (I argue for a more relational interpretation and development of Nussbaum's approach elsewhere).
} 
the assumption of a human essence. Self-development is intrinsically related to change in the world. This means that we can no longer be "pervaded" in an existentially relevant sense. What would be pervaded? In this view, there was never a pure state in the first place, no agent or self that is prior to "interaction". Being alive is being related. We need an epistemology and ontology of breathing here: we are in continuous touch with the world; we are in the world as changing and exchanging beings. This is how we gain knowledge and this is how we live.

Moreover, phenomenological ecology implies not only the death of the autonomous subject, but also the death of the autonomous object. There is no permanent, fixed ontological order. There are no "mere" objects or "mere" means. There are no artifacts apart from their relations to their environment, and there is no thing-in-itself (to use a famous Kantian term). With regard to the human-technology relation, we must question isolationist assumptions with regard to the meaning of the terms "human" and "technology": there are technohuman ecologies, in which "things" and "humans" are interdependent in a strong sense: they cannot exist without one another. For humans, this "deep relationality" implies that we do not 'have' an environment but are environmental by nature. In this sense, the modern, largely Cartesian philosophical project is a suicidal project: if we disconnect ourselves from the world, create a split between subject and object, we end our lives, rip apart the connection we are.

Spiritually, these non-dualistic views imply that spirit is not the possession of the One, or given by the One, as monotheism supposed, and they question the sharp separation of appearance and reality inherent in Platonism. To start with the latter, Platonism is notoriously dualistic, and insofar as the Western philosophical tradition is influenced by Platonic thinking, it inherits this dualism. To question this tradition means to explore "non-Platonic" views in philosophy ${ }^{8}$ and religion. Non-dualistic views of

\footnotetext{
${ }^{8}$ Criticism of the Platonic strand in the Western philosophical tradition (and indeed of monotheism) has become rather common by now - to the point of becoming a cliché-but it remains an interesting direction of thought for those who wish to explore more 'earthly' views of the world, of spirituality, of human beings, and of technology (but still different from the scientific world view). For example, Onfray has criticized the monotheist religions and the Western philosophical project for their Platonism. In his Atheist Manifesto, he writes that monotheists turned to Plato in order to focus on the eternal and the immortal; they "conceive of the earthly city only in terms of the heavenly city', thus creating a gap between earthly and heavenly concerns that became 'an ontological wound impossible to close." (Onfray 2005, p. 96) He has defended an antiPlatonic approach that is to get us closer to the earth, to matter, to the body, and to the senses. (Note, however, that he also defends hedonist and (post) anarchist versions of this view, which are not necessarily implied in the broader anti-Platonic stance he proposed. Moreover, the ideas I explore in this paper need not necessarily be a-theist, and some interpretations of monotheist spirituality might be closer to 'the earth' than Onfray suggests.).
}

spirituality do not presuppose an ontological or spiritual gap between "higher" and "lower", "spiritual" and "material", "mind" and "matter". Rather, spirituality itself becomes "ubiquitous": spirit is everywhere-or indeed nowhere (as Eastern thinkers know, on these matters, we can only speak paradoxically). However, this view does not only resemble some influential strands in Eastern thinking, but is also close to "polytheistic" nature religions that preceded Western monotheism and preceded Eastern "religions", for example "pagan" (that is, non-Christian) religion in Western Europe and Shintoism in Japan. Both Western paganism and Shintoism believe that there are spirits and gods in various places and objects. Spirit does not belong to one god or to one kind of beings (the children of the one god) but is "ubiquitous" and pervasive and not traceable back to one source. Soul is everywhere or can be everywhere, spread throughout the world and 'in' the world, rather than a priori disconnected from it.

This view seems to commend forms of immanent spirituality rather than transcendent spirituality. ${ }^{9}$ Moreover, such spirituality also implies that we must question the story of "disenchantment" (Weber 1919), inspired by nondualistic approaches; we must deny that our world is (necessarily) a place of alienation and open up to different ways of experiencing the world. If we do so, we may replenish the world with meaning and value, or rather, from this perspective, we may come to experience it as always having been full of meaning and value. ${ }^{10}$

Similarly, according to this view, the social is not defined in a way that disconnects it from the larger, living natural-artificial whole. Society is already technological, and technology is already social. Society is not constructed by pre-social and de-material individuals, but grows out of, and with, the natural and the material. The social is neither separated from technology nor from nature. In lived experience and practice, in existence-in-development, all modern categories merge and provide the relational ground for human flourishing. ${ }^{11}$

For ethics of technology, these alternative anthropologies, ontologies, spiritualities, and sociologies imply that we must replace the ethics of control and autonomy by an ethics of life, which is concerned not with protecting the boundaries of the self and the human against invasion and pervasion by technology, but with shaping and re-shaping the continuously changing human-technology relations.

\footnotetext{
${ }^{9}$ Note, however, that neither immanent nor transcendent spirituality exists in 'pure' form; most religions are a mixture of both.

${ }^{10}$ For arguments against disenchantment theory, see for example, Bennett (2001) and Szerszynski (2005). See also my discussion of the relation between spirituality and technology in Coeckelbergh 2010.

11 Note also that in light of the view of spirituality articulated above, the social is not only material but also spiritual. The history of society is also the history of the sacred (see also, Szerszynski 2005).
} 
The question is not, "Do we let this technological artifact enter our lives" but "Is this artifact contributing to a good way of relating to our environment?" Is this artifact a good fertilizer for the growth of good, for human and non-human flourishing? Such an "environmental" ethics requires some kind of "agency," perhaps, but then not understood in terms of the thoughts (or the "mental", e.g., intentions) and actions of a subject divided from objects, but rather holistically and in terms of adaptation and growth. In ethical action, the mental and the material merge, there is human/technological and human/non-human flourishing.

This kind of ethics does not take away the possibility to be critical about new technologies and does not take away the possibility of (understanding and justifying) fear of particular technologies. We may come to experience that some technologies we are involved with produce less flourishing. However, what is to be feared here, then, is not that the technology in question "takes over" (because philosophically speaking there is nothing separate to take over), but that the technology threatens life, produces death - with death understood as the absence of connection and change, indeed alienation. Then alienation is neither the pervasion of the self by something alien nor, as in Marx, a distance between worker and product (see e.g., the Economic and Philosophic Manuscripts of 1944), but the denial of the deeper existential and dynamic relationality implied in human being and the active attempt to disconnect rather than link.

Thus, this approach to human being and to technology does not exclude normative evaluation of technologies, on the contrary. If anything or anyone fosters and reinforces ways of thinking and doing that disconnect us from our environment broadly conceived, that is, if it attempts to violate and annihilate relations-relations of all kinds, in dualist language, "human-human", "human-natural", "human-artificial", "natural-natural", etc.-then this is bad ethically speaking. If there is anything we must fear, it is that kind of "alienation" (Note, however, that this kind of ethics does not necessarily require a heuristic of fear: even the fear of death can be overcome according to Taoists-if life and death both belong to Tao, if they are one, then fear ceases).

With regard to information technology, for example, this kind of ethics implies that if flows of information and communication become ubiquitous and pervasive, "mixing" themselves with the objects of our "lifeworld", this is not necessarily problematic. The modern illusion that this "lifeworld" was separated from "the system" in the first place and the illusion of the possibility of full control are themselves problematic. However, as said if certain "technological" developments were to promote human living in a way that leads to isolation from our social, natural, and artificial environment, that undermine the living ecological whole, then such growth would not lead to flourishing and can rightly be called "bad". Note, however, that usually "technological" developments (which are at the same time social and human developments) are ethically ambiguous. For example, the World Wide Web has helped us to become more interconnected, both with each other and perhaps also with the (global) "natural" world. At the same time, however, it also provides a platform for self-centered pursuits that seek to expand power and control of individuals at the expense of human and non-human others, rather than strengthening relations.

Viewing from this perspective, if there is a problem of hubris at all, it is not that technology may turn against us and control us, whereas we should be in control. The problem of modern hubris is that we think we can be disconnected and should be disconnected, that we are and should become psychologically, socially, and ontologically autonomous individuals, separated our social-naturalartificial environment. This descriptive and normative solipsism is the hubris inherent in modern dualistic thinking. But, as Heidegger also warned us, we should not entertain the illusion that we can simply get rid of this way of thinking. Let me explain this.

\section{Modernity's pervasiveness, artificial intelligence, and the growth of cultural change}

In his later philosophy, Heidegger criticizes the view that technology is a means to an end (Heidegger 1954) and suggests that the very attempt to control technology still belongs to the modern technological way of thinking and excludes other ways of thinking. Instead of trying to control, he says that we have to let go (Heidegger uses the term Gelassenheit, Heidegger 1999). This means that we have to wait for change to happen. Truth is a revealing and an unfolding; although it does not happen without humans, it does not happen exclusively through humans, and we may never see the ultimate truth. Many stars in the nocturnal sky have long since died; who can say with certainty what is really happening now? Perhaps modern thinking is dying or has already died. Yet at the same time, in our current experience it shines forth or appears to shine forth now for $u s$ and pervades our thinking and doings. We cannot fundamentally, radically, and quickly change this situation by means of "meta-technology". Of course, we can make and enforce regulations, laws, etc., to try to make (the use of) technology more "ethical"; like technology, these are means of exercising control. But if we presuppose that we can control the world in this way, our meta-technology itself is also a modern technological way of thinking; it is part of the problem rather than its remedy. 
Moreover, if everything is inter-dependent in a strong sense, we cannot change our thinking and "re-enchant" the world by a mere act of will. If our way of thinkingincluding the illusion that the world is disenchanted-can change at all, it cannot change because we want it to change. Our way of thinking and doing has already changed human being and the world we are entangled with. To think that we could "switch" to a different thinking and spirituality would assume the very modern kind of thinking it seeks to replace; it is only by supposing that the world is an empty canvas on which we inscribe our meaning and our values, that we could even consider the possibility that the world might be "disenchanted" or "re-enchanted" at will. Humans cannot do this. And what kind of god could do it? It would take a very "modern" god indeed to reconfigure or "reset" the moral and spiritual status of the world. Only a man-made artifact like a computer can be "reset", and the world is not our artifact-if it is one at all.

Does this mean that no cultural change is possible, that our thinking must remain captive? Although technology in the broad sense outlined above has always been "pervasive," the modern way of thinking and doing is not necessarily pervasive, although for now it is pervasive in the Western World and also in the Eastern societies, insofar as they are infused with, and mixed with, modernity. But this insight by itself can already open up our thinking and attend us to alternative ways of seeing and doing, allowing us to be critical of our current vocabulary and thinking.

Consider for example the way we think about information and information technology. In our modern language, we talk about information as if it is a "standing-reserve" (Heidegger 1954). We think it is a resource, which is available to us and which we can use. We treat information the way we treat natural or artificial objects, as means for human purposes. The same goes for the material artifacts that "process" information. This makes information and information technology appear as ethically neutral; it seems to be a mere tool. But by talking about information in this way, we forget that it can also be regarded as something that that also changes us and forms us. Since we are deeply relational, how we think about information and what we do with information changes our form of human being and our form of life. If we are not aware of this, it is because modernity - as a way of thinking and living-is itself pervasive, has become ubiquitous; it is present in our thinking, in our activities, and in our objects. It is part of us and it has shaped what it means to be human. Modern technology also forms modern subjects. Perhaps we could say that object and subject "live" in a kind of symbiosis. We cannot simply end a particular object-subject relation and the practice that is shaped by it.

At the level of the self, for instance, technologies play a more significant role than is usually supposed.
Technologies are not only tools and things but always also what Foucault called "technologies of the self"-techniques humans use to understand themselves and which "permit individuals to effect by their own means or with the help of others a certain number of operations on their own bodies and souls, thoughts, conduct, and way of being" (Foucault 1988, p. 18). But often we do not use these technologies-as-technologies-of-the-self in a conscious way. Although often unintended, the artifacts we use and design also shape the self. For example, we use social networks to "connect" to others but at the same time we constitute our identity.

Moreover, in on-line networks-social and commercial—our constructed identities are already treated as objects; we are used as data, that is, as a resource, for commercial purposes. By treating the world as a standingreserve, we have become a standing-reserve ourselves. But the solution is not to reinforce our autonomy, for example, by claiming privacy rights. If we treat it as a problem concerning autonomy, we remain in the same kind of thinking space. Rather, what is problematic and dangerous are the "I-phones" and the "I-way of thinking" on both sides of the debate, which exemplify the hyper-individualist modernity that denies its own relational ground. We risk to become the individuals we always wanted to be; we the risk absence of connection; we risk death - the death of the human, the death of the social, and the death of the spiritual (which amount to the same).

Again, (meta-) technological thinking will not help to change this situation. Modernity itself is not (entirely) produced, made by us, but is growing. The question is not "How can we construct walls against invasion by modernity?" or "How can we expel modernity from our fortified castle-society?" Modernity is us; we are modernity.

The desire to change is also modern, of course, and in modernity, we still have the desire to relate to the world and to others. With regard to the latter, consider the ethical ambiguity and indeed existential tragedy of modern social networks: their aim is to connect, but at the same time they threaten relationality (or at least deny it) insofar as they work as ego-boosters, since they are used as tools to (try) take distance from others and from the world, indeed to enact once again the Cartesian drama. In this way, the means change the end, and both means and end remain ambiguous. Do we become friends or masters and slaves? Are others collections of data or fellow travelers? The technology is "pervasive" in this deeper sense-we attempt to leave modernity but we remain modern, and this tension is in our use of technology. What we are is already pervaded by (late) modernity as a way of thinking and as a particular way of technological doing. But if we think that this particular way of thinking and doing is ethically problematic, there is no easy way to change this; it seems 
that, to some extent at least, we have to live in and with this tension and this tragedy.

Perhaps we need new myths or re-interpret old myths, to better understand our predicament. For example, in our mythology we could replace Prometheus by Narcissus. We love humanity and we love ourselves; we keep on looking in the mirror. But in the end, this absence of (real) relationality means death. Our mirror image does not answer. If we create technologies that show us what we are but fail to let us grow and flourish, we are on the wrong track-or rather we do not move at all. A famous scholar of Confucianism (Wei-Ming 1991) draws attention to the imperative "renew yourself every day". If we want to renew humanity, we need to renew our relation to technology. Modernity loves the new, but can it bring forth the new in such a way that it allows us to move beyond modernity, beyond itself?

For thinking about AI, this problem implies that we should think twice before creating entities in our image for a different reason than suggested by the "Frankenstein" way of framing the problem. We are right to fear the coming of such robots, but not because they (the artificial creatures) would necessarily turn against us (the creators) and punish our hubris, or not even because they would shock the human ego once again by challenging the idea that we are radically different from machines, as Mazlish has argued (Mazlish 1993), since this is yet another version of the hubris narrative. Rather, we are right to fear such a future if it means that these robots are indeed created in imago humani understood socially and historically, that is, if we would create relations between "them" and "us" that resemble current human relations and forms of life, since this would recreate the problem of modern society. Then, we would feel that we need once again a modern solution to a modern problem; our lives would become "solitary, poor, nasty, brutish, and short", as Hobbes described his "war of every man against every man" (Hobbes 1651), unless we would install new sovereigns (natural or artificial) and give up our initial freedom. But the modern problem definition is itself flawed since it denies that we-humans and non-humans-are already part of a living, social-natural--artificial whole. If we keep watching too long in the mirror, we lose sight of the real.

Today, the largest "artificial intelligence", however, is not in robots but is right before our eyes: the naturalartificial whole, the techno-human ecology, has grown into a World Wide Web and we are part of it. With regard to this "hybrid" ecology, the better ethical questions are not "Does it threaten our autonomy?" or "Does it alienate us?"- this presupposes that it is external to the humanbut rather "Can we begin to re-direct its growth"- that is, our growth-in a way that produces more flourishing rather than less? This means: can we change in a way that is more fruitful than what has grown out of the dry, sterile seeds of hyper-individualist modernity? Can we do this without falling into the trap of collectivism, fascism, "fundamentalism" and other modernisms and quasi-modernisms? Can we transform ourselves in a non-modern way, and how, given that this desire for transformation is typically modern? The stakes are high; the question about technology is at the same time the social question, and ultimately, a "religious" or "spiritual" question with a strong normative side to it: how and to what/to whom can we relate (Lat. religare; this is the broad meaning of religion assumed in this essay) and how should we relate?

In order to answer this question, we can try to learn from the study of non-modern forms of life and from alternative modernities in the East and elsewhere (see also Eisenstadt 2000 on "multiple modernities"). There is no "pure" form of modernity, not even in the West. And the alternative modernities we might perceive in the East or elsewhere are not fixed; they are themselves dynamic and they are growing into forms we cannot entirely grasp or predict. Moreover, these forms should not be understood separate from the West. For example, Chinese culture, like any other culture, is a "living reality" (Wei-Ming 1991), which was already impacted by Western modernity in colonial times and continues to be impacted by it today, and what grows out of this may in turn influence thinking in the West. In particular, it may challenge the Western way of life, including the specific Western way of being-technological and being-together (without necessarily resulting in a convergence).

Therefore, the question what it is to be human in this age of pervasive technology requires us to further reflect not only on the material, cultural, and spiritual conditions that form our lives in our society ("wherever" that is), but also on the conditions that shape the lives of people living in other societies. To stop looking in the mirror of our own culture implies being open to listen to different stories and try out different ways of relating. Technologies, cultures, and societies only become alien if we do no longer engage with them, and the same is true for our own culture: we experience our own world as alien if we disconnect, if we stop breathing. Living means: the world goes through us and we go through the world. It is to pervade and to be pervaded. A living culture breaths. But an ethics of life should not be conceived as a meta-technological modernist project of regaining control and executing a plan to change our culture by forcing in a different way of thinking (this would amount to a kind of "self-colonization"). Impatience is perhaps the modern vice. Rather, virtuous cultural change must be understood and practiced as a way of letting-grow - a growth, a metamorphosis which is at the same time human, social, technological, and spiritual. 
Open Access This article is distributed under the terms of the Creative Commons Attribution License which permits any use, distribution, and reproduction in any medium, provided the original author(s) and the source are credited.

\section{References}

Bacon F (1626) The New Atlantis. Retrieved from http://www. gutenberg.org/files/2434/2434-h/2434-h.htm

Benjamin W (1936) The work of art in the age of mechanical reproduction. In: Arendt $\mathrm{H}$ (ed) (1968) Illuminations (trans: Zohn H). Schocken Books, New York

Bennett J (2001) The enchantment of modern life: attachments, crossings, and ethics. Princeton University Press, Princeton

Berlin I (1958) Two concepts of liberty. Reprinted in the Proper study of mankind: an anthology of essays. Chatto \& Windus, London, 1997

Callicott JB (1986) The metaphysical implications of ecology. Environ Ethics 8(4):301-316

Coeckelbergh M (2010) The spirit in the network: models for spirituality in a technological culture. Zygon: J Religion Sci 45(4):957-978

Eisenstadt SN (2000) Multiple modernities. Daedalus 129(1):1-29

Foucault M (1988) Technologies of the Self. In: Martin LH, Gutman H, Hutton PH (eds) Technologies of the self: a seminar with Michel Foucault. The University of Massachusetts Press, Amherst

Habermas J (1984-1987) The theory of communicative action (trans: McCarthy T). Cambridge, Polity

Heidegger M (1927) Being and time (Trans: Stambaugh J). SUNY Press, Albany, NY, 1996

Heidegger M (1954) The question concerning technology. In: DF KrellMartin heidegger: basic writings (trans: Lovitt W). Harper \& Row, New York, 1977
Heidegger M (1999) Gelassenheit. Neske, Stuttgart

Ho DYF (1995) Selfhood and identity in confucianism, taoism, buddhism, and hinduism: contrasts with the west. J Theory Soc Behav 25(2):115-139

Hobbes T (1651) Leviathan. Clarendon Press, Leviathan. Oxford

Latour B (1993) We have never been modern (trans: C Porter). Cambridge University Press, Cambridge, MA

MacIntyre A (1999) Dependent rational animals. Open Court, Chicago

Mazlish B (1993) The fourth discontinuity: the co-evolution of humans and machines. Yale University Press, New Haven

Nussbaum M (2006) Frontiers of justice: disability, nationality, species membership. Harvard University Press, London and Cambridge, Mass

Nussbaum M (2011) Creating capabilities: the human development approach. The Belknap Press of Harvard University Press: Cambridge

Onfray M (2005) Atheist manifesto: the case against christianity, judaism, and islam (trans: Jeremy L). Arcade Publishing, New York, 2007

Sartre J-P (1946) Existentialism is a humanism. (trans: Philip M). Methuen, London, 1948

Szerszynski B (2005) Nature, technology and the sacred. Blackwell, Oxford

Varela F (1999) Ethical know-how: action, wisdom and cognition. Stanford University Press, Stanford, CA

Varela F, Thomson E, Rosch E (1991) The embodied mind. MIT Press, Cambridge, MA

Weber M ([1919] 1946) Science as vocation. In: Gerth HH, Mills CW (eds) From Max Weber: essays in sociology (trans: HH Gerth, CW Mills). Oxford University Press, New York, pp 129-56

Wei-Ming T (1991) Cultural China: the periphery as the center. Daedalus 120(2):1-32 